\title{
The secret program of US. mind control weapons: is it developing in latin America?
}

\section{Opinion}

For many people, the mind control, is a topic of science fiction or of psychiatric disorder rather than science, however, in the $21 \mathrm{st}$ century, the advance in neuroscience leads to a scientific reality that is opposite to such perception, a reality that all doctor needs to know.

"Mind control is a reductive process in which a man is reduced to an animal or machine"l

The mind control has been tried through history in different ways, like the physical violence or the religion; some governments have been obsessed with mind control, especially, and those that tended to fascism, like the Nazis. ${ }^{1}$

The basic ideas of mind control originated in 1921, in Tavistock, a research center of the British Intelligence Service, and then they were developed in Germany, mainly in the Nazi concentration camp, Dachau. ${ }^{1}$ The main mind control operations began in 20th century through institutions like the CIA, dedicated to promote the New World Order, the long-term plan to create a single oligarchic government in the world ${ }^{1}$ The United States of North America is the first world military power; it is critical for such country to develop new weapons of war. Among the weapons that the USA has tried to develop are the weapons of mind control. ${ }^{2}$

United States, through its history, has developed different mind control experiments, from 1950 to 1972, with the participation of Nazi scientists recruited by the U.S. government: the BLUEBIRD, the MKULTRA, and the MKSEARCH.

The MKULTRA program developed by the CIA was a program designed to perform the largest mind control experiment, an illegal and clandestine program of experiments on human subjects. The experiment included the participation of scientists and 80 renowned institutions, among them 44 schools, prestigious universities like Harvard and Yale, 12 hospitals, and pharmaceutical companies, and jails. ${ }^{2}$ It was a project that included 149 subprojects, all related to the mind control. At least 139 drugs were investigated.

The chemist Joseph Schneider, known as Sidney Gottlieb, "Doctor Death ", was responsible for the MKULTRA and MKSEARCH projects, experiments designed to weaken human mental resistance; through different methods ${ }^{2}$ Gottlieb created in the Peruvian jungle, Iquitos, the Amazon Natural Drug Company, a covert company; its purpose was to compile the hallucinogenic and toxic components of Peruvian jungle plants, for CIA laboratories, ${ }^{3}$ although the MKULTRA project used mainly hallucinogenic drugs, being the LSD one of the most used drugs, ${ }^{1}$ experimental stimulation techniques of deep brain areas were also used.

Nowadays, with the modern advances in science, mind control could be developed with brain nanobots, microchips and implants, which have only been used in human beings to improve health. U.S. Department of Defence through DARPA agency has informed that it has developed brain implants to improve its army health.

The US government has denied the existence of a mind control weapon program nowadays; however, the existence of technology
Volume 3 Issue 2 - 2018

\author{
David Salinas Flores \\ Faculty of Medicine, Universidad Nacional Mayor de San Marcos, \\ Peru
}

Correspondence: David Salinas Flores, Faculty of Medicine, Universidad Nacional Mayor de San Marcos, Peru, Tel +5 I I 996 37I 790,Email dsalinas2009@yahoo.com

Received: March 27, 2018 | Published: April 02, 2018

capable of creating it suggests the existence of a classified mind control weapon program. ${ }^{4}$ Thus, one of the developed devices is a cortical modem ${ }^{5}$ that turns digital signals into analogical ones. Computers process information in digital form, the phone lines only process analog signals, thus with the implantation of these brain modems, the digital information of the human brain computer can be turned into analogue signal and transmitted by phone, and viceversa, thus images can be sent to and received by the human brain, however, these modems could be used also as a mind control weapon; sending audiovisual signals to the visual cortex could be used as mental torture, brain mapping obtained with the modem could serve for mental reading and to steal a citizen's private information, which could be used to extort the victim and control him, thus the great danger is that they could be implanted in citizens secretly and forcibly as a mind control weapon.

Recently the president of the United States of North America, Barack Obama, has presented the BRAIN project. In addition to USA, the European Community and China also develop very similar brain research projects. In China, it is also called BRAIN project and in Europe, HUMAN BRAIN project. The project is developed together with multinational corporations linked to the economic powers (Figure 1).

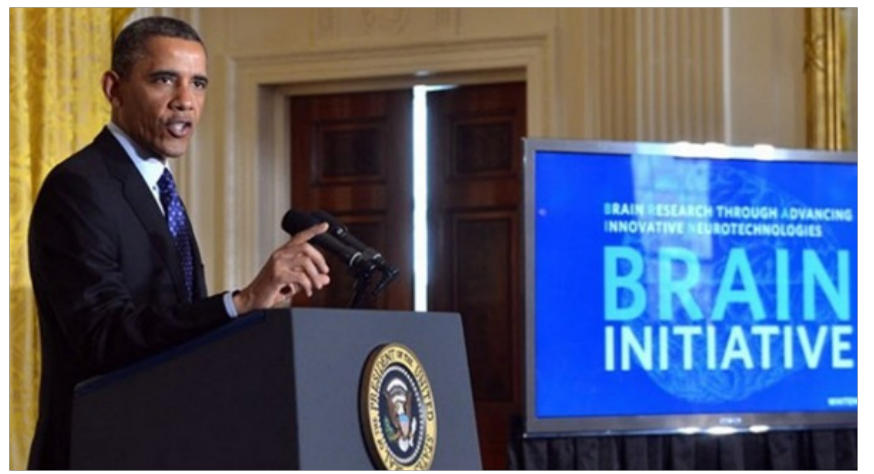

Figure I The President of the United States of America Barack Obama announcing the BRAIN project, Source. ${ }^{6}$

Rafael Yuste, an main scientist of the BRAIN initiative has publicly stated that the main objectives of the project is manipulate neurons (Figure 2), therefore a different interpretation is that the BRAIN 
Project would be really a project organized by the economic powers to investigate the brain in order to develop mind control weapons, ${ }^{6}$ new weapons that could be a threat for world health, and that would seek to establish a future fascist world government.

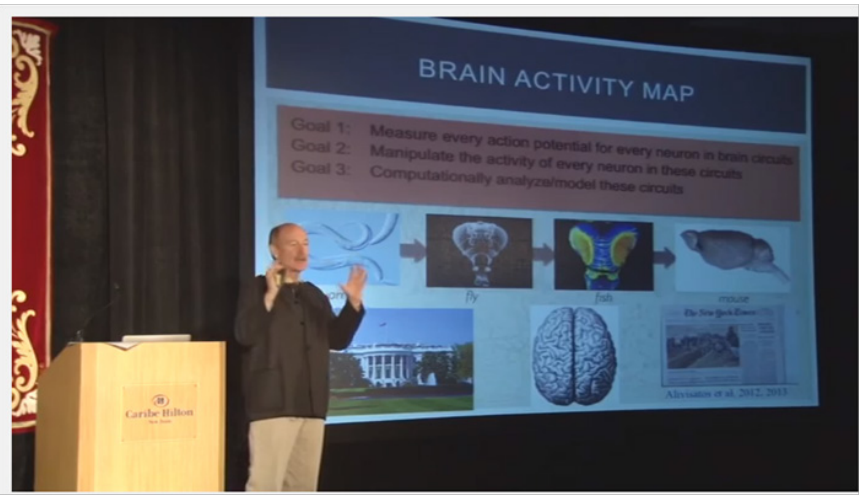

Figure 2 Neurons control to mind control Rafael Yuste, an main scientist of the BRAIN initiative has publicly stated that the main objective of the project is manipulate neurons, therefore there is suspect that BRAIN initiative is a secret research program of mind control that is being developed in Latino America.

The public knows about the power of nuclear weapons, and can debate and protest; on the other hand, it is known that mind control weapons are being developed, but they are surrounded by denials and disinformation from the U.S. government, therefore, the population cannot debate their existence and danger. U.S. mind control weapons can be more powerful than the atomic bombs; their existence remains as one of the greatest secrets of the USA. ${ }^{4}$ The U.S. government tries to deny the existence of mind control weapons, but even in the age of information, inhuman and horrific events happen with the complicity of silent witnesses; therefore, mind control experiments could be happening today. ${ }^{4}$ Latin America, unfortunately, has a long history of unethical human experimentation, like the one that took place in Guatemala, which the current administration of President Barack Obama qualified as ethically impossible.?

Nowadays, recent researches lead to suspicion that others projects related to mind control and artificial intelligence would be carried out based on illegal human experiments with brain nanobots performed in Latin America, as like in manufacturing neuromorphic chips of IBM and INTEL; or the creation of real zombies, ${ }^{8-10}$ based on this suspicion it is likely that also the secret program of US. Mind control weapons are being developed in Latino America. Doctors and citizens must be on the alert for these bad applications in neuroscience.

\section{Acknowledgements}

None.

\section{Conflict of interest}

Authors declare that there are no conflicts of interest.

\section{References}

1. Keith J. Mind Control, World Control. 1st ed. Kempton, IL: Ilinois Adventures Unlimited Press.1998.

2. Project Mkultra. The CIA's Program of Research In Behavioral Modification U.S. Senate: Joint Hearing before The Select Committee on Intelligence and The Subcommittee on Health and Scientific Research of the Committee on Human Resources, 95th Cong., 1st Sess. August 3; 1977.

3. Smith T. Enciclopedy of The Central Intelligency Agency. New York: Infobase Pub; 2003.

4. Cheryl W. The 2006 Government Mind Control Debate: Book review of Mind Wars: Brain Research and National Defense by Jonathan D Moreno; 2006 .

5. Cuthberston AD. Cortical Modem connects brain directly to computer for "electronic telepathy and telekinesis" International business Review February 18; 2015

6. Salinas D. El Proyecto BRAIN: Sólo se estudia en computadoras?. Rev Med Chile. 2015;(8):1081-2.

7. Presidential Commission for the Study of Bioethical Issues" éticamente imposible "Investigación sobre las STD en Guatemala desde 1946 hasta 1948. Washington DC; 2011.

8. Salinas D. The secret of neuroscience boom: Are there secret human experiments in Latin américa?. Egypt J Intern Med. 2016; 28(1):1-4.

9. Salinas D. Proyecto Cerebro Humano: ¿Existen Experimentos humanos secretos en Latinoamérica? Arch Med. 2016;16(1):192-8.

10. Salinas D. El secreto de Hollywood: Zombis creados por nanobots cerebrales. Medicina y Cine; 2018. 